\title{
Expression of two microRNAs, ame-mir-276 and -1000, in the adult honeybee (Apis mellifera) brain*
}

\author{
Sayaka HoRI $^{1,2, * *}$, Kumi KANEKO $^{1, * *}$, Takeshi H. SAITO ${ }^{1}$, \\ Hideaki TAKEUCHI ${ }^{1}$, Takeo KUBO ${ }^{1}$ \\ ${ }^{1}$ Department of Biological Sciences, Graduate School of Science, The University of Tokyo, 7-3-1, \\ Hongo, Bunkyo-ku, 113-0033 Tokyo, Japan \\ ${ }^{2}$ Department of Physiology, Tokyo Women's Medical University School of Medicine, 8-1, Kawada-cho, \\ Shinjuku-ku, 162-8666 Tokyo, Japan
}

Received 20 July 2009 - Revised 8 January 2010 - Accepted 8 January 2010

\begin{abstract}
To identify candidate microRNAs involved in post-transcriptional regulation of brain (region)selective gene expression in the adult honeybee brain, we isolated eight microRNAs: seven known microRNAs, ame-mir-2-1, -8, 13a, -34, -276, -317, -1000, and one novel one, named mir-hbd, that has significant sequence similarity with the Drosophila dme-mir-11. Among them, ame-mir-1000 and -276 were expressed in a brain-selective and -preferential manner, respectively, in workers and drones. In particular, ame-mir-276-expression was enriched in the optic lobes and in the small type-Kenyon cells of the mushroom bodies in the nurse bee, forager, queen, and drone brains. Almost all predicted targets of amemir-1000 and -276 encode neural function related genes, suggesting the involvement in neural function of both microRNAs.
\end{abstract}

brain / microRNA / Apis mellifera / honey bee / gene expression

\section{INTRODUCTION}

The European honeybee (Apis mellifera L.) is a social insect and the female adults differentiate into two castes: queens (reproductive caste) and workers (labor caste) (Winston, 1987; Robinson et al., 1997). Queens are devoted to laying eggs, whereas workers shift their labors depending on their age after adult emergence: young workers (usually 7-14 days old) are engaged in nursing their brood, while older workers (usually older than 12 days)

Corresponding author: S. Hori, horis@ research.twmu.ac.jp

\footnotetext{
* Manuscript editor: Klaus Hartfelder

** These two authors contributed equally to this work.

Online material is available at:

http://www.apidologie.org
}

forage for nectar and pollen (Winston, 1987). Drones are engaged only in mating with queens. Therefore, the honeybee is an excellent model for the analysis of the molecular and neural bases underlying animal social behaviors.

The honeybee brain comprises several regions, including the optic lobes (OLs, a visual center), the antennal lobes (ALs, an olfactory center), and the mushroom bodies (MBs, a higher order center). Compared with some solitary insects, honeybee MBs are welldeveloped (Mobbs, 1982). The proportion of the honeybee MBs varies according to the division of labor of the workers (Fahrbach et al., 1995), suggesting that MB function might be related to their division of labor. Honeybee MBs are composed of three intrinsic neurons, termed large-, and class I and class II small type-Kenyon cells (Mobbs, 
1982). Recent studies revealed that the largeand small type-Kenyon cells have distinct gene expression patterns (Kubo, 2003; Paul et al., 2006). Furthermore, the expression of some genes in the MBs changes according to the division of labor of workers (Ben-Shahar, 2005; Yamazaki et al., 2006; Denison and Raymond-Delpech, 2008; Heylen et al., 2008). We previously demonstrated that expression of HR38, which encodes a nuclear hormone receptor, is enriched in the small-type Kenyon cells in the worker brain and increases according to the division of labor of workers, suggesting that the change in the mode of ecdysone-signaling in small-type Kenyon cells is related to the division of labor (Yamazaki et al., 2006). In addition, we used a novel immediate early gene, termed kakusei, to show that the small-type Kenyon cells are active in the forager brains (Kiya et al., 2007). Moreover, Robinson et al. have reported large-scale transcription profiles of genes from the honeybee nervous system related to social behavior (Robinson, 2002; Whitfield et al., 2003; Adams et al., 2008; Ament et al., 2008; Alaux et al., 2009; Brockmann et al., 2009). Analysis of the molecular mechanisms regulating brainand/or brain region-preferential gene expression is an important step toward understanding the molecular basis of honeybee social behaviors. The post-transcriptional regulation underlying honeybee social behaviors, however, remains largely unknown.

Over the last decade, microRNAs (miRNA) have been identified as important posttranscriptional regulators. Mature microRNA is processed from the stem of $\sim 70 \mathrm{nu}-$ cleotide (nt) stem-loop structures, called premicroRNAs, by Dicer (Bartel, 2004), and are tiny (approximately 22-nt in size) noncoding RNAs that regulate gene expression by repressing translation or messenger RNA (mRNA) degradation. Some microRNAs have been verified or predicted to regulate up to hundreds of targets (Krek et al., 2005; Lim et al., 2005), and some intronic microRNA could also suppress antagonistically to its host gene (Barik, 2008). microRNAs typically bind to the $3^{\prime}$-untranslated region (UTR) of target genes with a canonical ( $5^{\prime}$ and $3^{\prime}$ similarity), seed (six [2-8] nt in $5^{\prime}$ ), or $3^{\prime}$ compensatory
(3' similarity) sequence (Bartel, 2004), and their binding sites are often conserved among related species (Brennecke et al., 2005).

Many functional microRNAs were recently identified from many eukaryotic organisms. In accordance with their many functions, some are expressed in developmental stage-specific (Stefani and Slack, 2008), tissue-specific (Babak et al., 2004) and/or sex-specific manners (Mishima et al., 2008). Some mammalian microRNAs are expressed in a brainpreferential manner and function in neuronal differentiation (Smirnova et al., 2005; Schratt et al., 2006), synaptic plasticity (Wayman et al., 2008), and the regulation of behaviors (Kosik, 2006; Karres et al., 2007). Thus, it is possible that some microRNAs have a role in regulating tissue- and/or brain regionpreferential gene expression in the honeybee, and in understanding the biological basis of behavior. Weaver et al. (2007) have predicted various microRNAs in the honeybee genome that were validated using RNA samples enriched for brain and thorax tissues. Therefore, there are no other reports about honeybee microRNAs expressed in a brain preferential/selective manner. In the present study, we identified candidate microRNAs involved in neural functions and analyzed their expression.

\section{MATERIALS AND METHODS}

\subsection{Cloning of cDNAs for microRNAs}

European honeybees had purchased from the Kumagaya Honeybee Farm (Saitama, Japan), and maintained at the University of Tokyo were used. Small RNAs $(<200 \mathrm{nt})$ were extracted from the worker brain using a mirVana microRNA Isolation Kit (Ambion). After subjecting the small RNAs $(2.2 \mathrm{mg})$ to $15 \%$ denaturing polyacrylamide gel electrophoresis, $950 \mathrm{ng}$ small RNAs were purified from the gel portion corresponding to 16 to $28 \mathrm{nt}$ using a small RNA Gel Extraction Kit $(\mathrm{TaKaRa})$. After they (33 ng) were ligated with 5'- and 3'- adaptors using small RNA Cloning Kit (TaKaRa), their cDNAs were PCR-amplified $\left(94{ }^{\circ} \mathrm{C}\right.$ for $2 \mathrm{~min}$, followed by 15 cycles of $94{ }^{\circ} \mathrm{C}$ for $30 \mathrm{~s}, 60{ }^{\circ} \mathrm{C}$ for $30 \mathrm{~s}$, and $72{ }^{\circ} \mathrm{C}$ for $30 \mathrm{~s}$, and $72{ }^{\circ} \mathrm{C}$ for $3 \mathrm{~min}$ ), and cloned. Insert sequences were analyzed using an ABI 3100 sequencher ver. 3.1 (Applied Biosystems) with T7 and 
SP6 primers. Homology searches were performed using miRBase database (http://microRNA.sanger. ac.uk/sequences/index.shtml). The secondary structure of mir-hbd precursor was predicted using Genetics Mac software version 11.1.0.

\subsection{Northern blot analysis and in situ hybridization}

Brains, heads without brains, thoraxes and abdomens were dissected from workers and drones. Small RNAs (<200 nt, 500 ng) were subjected to Northern blot analysis, using digoxigenin (DIG)-labeled Locked Nucleic Acid (LNA) probe, as previously described (Weaver et al., 2007). The probes used were: ame-mir-276 probe, 5'agagcacggtatgaagttccta- $3^{\prime}$; scramble-miR probe as a negative control, $5^{\prime}$-ttcacaatgcgttatcggatgt- $3^{\prime}$, and ame-mir-1000 probe: $5^{\prime}$-actgctgtgacaagacaatat-3', (purchased from Hokkaido System Science Co., Ltd.). LNA is a novel bicyclic high-affinity RNA analogue that has high hybridization affinity toward cDNA (Vester and Wengel, 2004).

In situ hybridization was performed as previously described (Yamazaki et al., 2006) and according to the manufacturer's protocol. Foragers and nurse bees were collected based on their behaviors (Yamazaki et al., 2006). Drones were collected in the hive. Queens were purchased from the Kumagaya Honeybee Farm (Saitama, Japan). Frozen vertical brain sections (10 $\mu$ m thick) were fixed in $4 \%$ paraformaldehyde in phosphate buffer, pretreated, and hybridized with the abovementioned DIG-labeled LNA probes (ame-mir-276 probe, scramble-miR probe as a negative control, and ame-mir-1000 probe). After stringent washes, DIG-labeled LNA probes were detected immunocytochemically with alkaline phosphatase-conjugated anti-DIG antibody using a DIG Nucleic Acid Detection Kit (Roche). Intensity and brightness of the micrographs were processed with Photoshop software (Adobe Systems).

\subsection{Target prediction}

We searched for honeybee homologues of the verified microRNA target genes in other species based on canonical, seed, or $3^{\prime}$ compensatory sequences of the predicted $3^{\prime}$-UTR. We also analyzed homologues of the predicted targets with the top 10 highest scores using TARGETSCAN (Kheradpour et al., 2007; Ruby et al., 2007) and/or
PICTER-FLY (Grün et al., 2005) in Drosophila, which no verified one has been known (http:// targetscan.org/, http://pictar.mdc-berlin.de/, respectively).

\section{RESULTS}

\subsection{Cloning of microRNAs from the honeybee brain}

To identify microRNAs involved in regulating gene expression in the honeybee brain, we first isolated microRNAs expressed in the honeybee brain. Small RNAs (<200 nt) extracted from worker brains were subjected to electrophoresis and small RNAs contained in the gel portion corresponding to 16 to $28 \mathrm{nt}$ were purified and cloned. A miRBase search revealed that 20 of the 45 isolated clones were identical to 7 known honeybee microRNAs (Tab. I). ame-mir-2-1 and -13a belong to the same family and cluster (Weaver et al., 2007). Clustered microRNA genes are often co-expressed for the coordinated control of related biological processes (He et al., 2005; Fiore et al., 2009). Our result suggested that ame-mir-2-1 and -13 are co-expressed and have the same function in the honeybee brain. The nucleotide lengths of ame-mir-2-1, -8, -13a, -34, -276, and -1000 were 1 to $2 \mathrm{nt}$ shorter or longer at the $3^{\prime}$ region than those of the registered sequences, which is often observed among various microRNA (Obernosterer et al., 2006; Long and Chen, 2009; Reddy et al., 2009). There are at least two possible explanations; one is that microRNA size actually varies in vivo, and the other is that either the microRNAs registered in the miRBase or isolated in our study represent partly degraded products. They are registered in the miRBase as intergenic genes in the honeybee genome, but we found that all of them were coded in introns of some hypothetical genes (Tab. I).

In addition, we identified one novel honeybee microRNA, mir-hbd (honeybee brainderived) that had the highest sequence similarity with Drosophila dme-mir-11 (81\%: 17/21 nt). Nucleotide substitutions deviating from dme-mir-11 were scattered throughout the mir-hbd cDNA sequences (Tab. I). Based 
Table I. Summary of the microRNAs isolated from the honeybee brain *The longest cloned sequence is shown when there are the size differences. Similarity was searched against the miRBase database (Griffiths-Jones et al., 2008). mir-hbd sequences that differ from Drosophila dme-mir-11 are underlined.

\begin{tabular}{|l|c|c|c|l|}
\hline \multicolumn{1}{|c|}{$\begin{array}{c}\text { Sequence* } \\
5^{\prime} \rightarrow 3^{\prime}\end{array}$} & $\begin{array}{c}\text { Number } \\
\text { of clones }\end{array}$ & $\begin{array}{c}\text { Related } \\
\text { microRNA }\end{array}$ & $\begin{array}{c}\text { Similarity } \\
(\%)\end{array}$ & \multicolumn{1}{|c|}{ Genome context } \\
\hline UAUCACAGCCAGCUUUGAUGAG & 3 & ame-mir-2-1 & 100 & $\begin{array}{l}\text { similar to Serine/threonine-protein } \\
\text { phosphatase 4 regulatory subunit } \\
\text {-like intron }\end{array}$ \\
\hline UAAUACUGUCAGGUAAAGAUGU & 1 & ame-mir-8 & 100 & $\begin{array}{l}\text { hmm21703 (similar to zinc finger, } \\
\text { CW type with PWWP domain 1) } \\
\text { intron }\end{array}$ \\
\hline UAUCACAGCCAUUUUGAUGAGCU & 3 & ame-mir-13a & 100 & $\begin{array}{l}\text { similar to Serine/threonine-protein } \\
\text { phosphatase 4 regulatory subunit } \\
\text { 1-like intron }\end{array}$ \\
\hline UGGCAGUGUUGUUAGCUGGUUGUG & 4 & ame-mir-34 & 100 & $\begin{array}{l}\text { similar to CG11246-PA } \\
\text { (LOC411083) 3' intron }\end{array}$ \\
\hline UGAACACAGCUGGUGGUAUCU & 1 & ame-mir-317 & 100 & $\begin{array}{l}\text { similar to CG11246-PA } \\
\text { (LOC411083) 3' intron }\end{array}$ \\
\hline AUAUUGUCUUGUCACAGCAGU & 1 & ame-mir-1000 & 100 & hmm610, intron \\
\hline CAUCACAGGCAGGAGUUCUAGU & 1 & dme-mir-11 & 81 & $\begin{array}{l}\text { intergenic (Genomic Contig Group } \\
\text { 9.15: 253727-253747 [-] ) }\end{array}$ \\
\hline
\end{tabular}

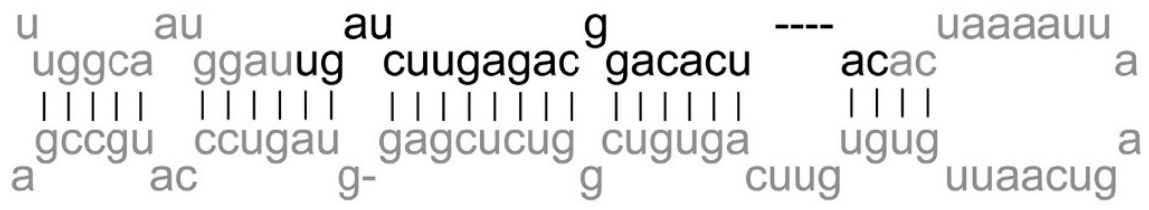

Figure 1. Secondary structure of predicted precursor for mir-hbd. Predicted stem-loop structure for the predicted mir-hbd precursor of $87 \mathrm{nt}$ in length. The mature microRNA sequence is indicated by black letters. The calculated minimum free energy was $-28.38 \mathrm{kcal} / \mathrm{mol}$.

on the genome sequences near its gene (GenBank accession NO. NW001253555), we predicted that the stem-loop structure of the 87-nt precursor contained this microRNA sequence (Fig. 1). As mir-hbd fulfilled two criteria for microRNA: (1) length (19-25 nt and 60$100 \mathrm{nt}$ for mature and precursor microRNAs, respectively), and (2) a stem-loop structure in the precursor (Kosik, 2006; Stefani and Slack, 2008). In the Drosophila genome, dme-mir11 clusters with dme-mir-998. Because microRNA clusters are often highly conserved with regard to genomic organization (Stefani et al., 2008), we searched for a honeybee mir-998 homologue by BLAST analysis of its genome. No obvious mir-998 homologue was observed, but two similar sequences were detected on different genome linkage groups (19/21 nt match on Group 5.12 genome: $1656790-1656810$ [+ strand], 18/20 nt match on Group 2.31 genome: 637013-637032 [- strand]). These results support the notion that mir-hbd is a novel honeybee microRNA rather than a conserved dme-mir-11 homologue. Similar sequences were detected in Homo sapiens and Oryza sativa genomes (Tab. II), but they did not contain the predicted stem-loop RNA structure (data not shown), suggesting that they are not mir-hbd homologues or paralogues. 
Table II. Hypothetical mir-hbd homologues. Sequences that differ from mir-hbd are underlined.

\begin{tabular}{|c|c|c|c|c|}
\hline Species & Sequence & Similarity $(\%)$ & Genome context & $\begin{array}{c}\text { 2nd structure around } \\
\text { microRNA }\end{array}$ \\
\hline Homo sapiens & CATCACAGGCATAGTTCTAGA & 90 & $5: 5078316-5078335[+]$ & not stem-loop \\
Homo sapiens & CATCACAGGCATAGTTCTAGT & 95 & $5: 22510861-22510881[+]$ & not stem-loop \\
Oryza sativa & CATCAGAGGCAGAGTTCTAGT & 95 & $4: 129940-129960[-]$ & not stem-loop \\
\hline
\end{tabular}

\subsection{Brain-preferential and brain-selective expression of ame-mir-276 and ame-mir-1000, respectively, analyzed by Northern blot hybridization}

Among the microRNAs isolated, we focused on two microRNAs for further expression analysis: ame-mir-276 and -1000. The largest number of ame-mir-276 clones obtained (Tab. I) suggested its strong expression in the brain. In addition, in Drosophila, dme-mir-1000, to which ame-mir-1000 is most closely related, is strongly expressed in both male and female adult whole heads (Ruby et al., 2007).

First, Northern blot hybridization using RNAs extracted from brains, heads without brains, thoraxes, and abdomens of workers and DIG-labeled ame-mir-276 LNA probe detected a single band of approximately $19 \mathrm{nt}$ size in all body parts, with the strongest density in the brain (Fig. 2A). In contrast, many small RNAs of almost similar density were detected in all body parts, when the polyacrylamide gel was stained with ethidium bromide (Fig. 2A), indicating brain preferential-expression of ame-mir-276. Although we obtained two types of ame-mir276 clones that were 19 and $21 \mathrm{nt}$ in length through cloning ( 3 and 5 clones, respectively), ame-mir-276 with $19 \mathrm{nt}$ was the major product in vivo. A similar expression pattern was observed in drones, suggesting its main role in the brain irrespective of the sex of the honeybees (Fig. 2B).

We next performed Northern blot hybridization using the DIG-labeled ame-mir1000 LNA probe. A single 23-nt band was observed specifically in the brain and not in the other tissues, in both workers (Fig. 2C) and drones (Fig. 2D), indicating its brain-selective expression. The band size (23 nt) was longer than the cloned one (21 nt), suggesting that two nucleotides were lost throughout the cloning procedure, or that the major products were longer than that of the cloned amemir-1000. Additional bands of approximately $73 \mathrm{nt}$ in size were also detected in all body parts. Because the size of the bands differed from that of the predicted ame-mir-1000 precursor (68 nt), it is likely that they represent other small RNAs that have sequence similarity with ame-mir-1000, but are not its precursors.

\subsection{In situ hybridization of ame-mir-276 in the honeybee brain}

We next analyzed the brain regionpreferential expression of ame-mir-276. In situ hybridization using brain sections of nurse bees, foragers, queens and drones and antisense LNA probes revealed that, although weak signals were detected in whole brain cortex in brains of all of these bees, stronger signals were detected in two restricted brain regions: (1) the OLs (Fig. 3A, C, K, $\mathrm{M}, \mathrm{O}, \mathrm{Q}, \mathrm{S}$ and $\mathrm{U}$ ); (2) the class I and II small-type Kenyon cells, whose somata are located at the inner core of the inside of the calyces and the outer bottom of each calyx, respectively, in nurse bee, forager and drone brains (Fig. 3A, B, K, L, S and T). Although, small type-Kenyon cell-preferential expression in the MBs was not so obvious in queens (Fig. $3 \mathrm{O}$ and $\mathrm{P}$ ), expression in the ALs and subesophageal ganglion was weaker than those in the OLs and MBs, in brains of all three phenotypes, workers, queens and drones (Fig. 3A, D, K, N, O, R, S and $\mathrm{V})$. In contrast, no significant signals were 

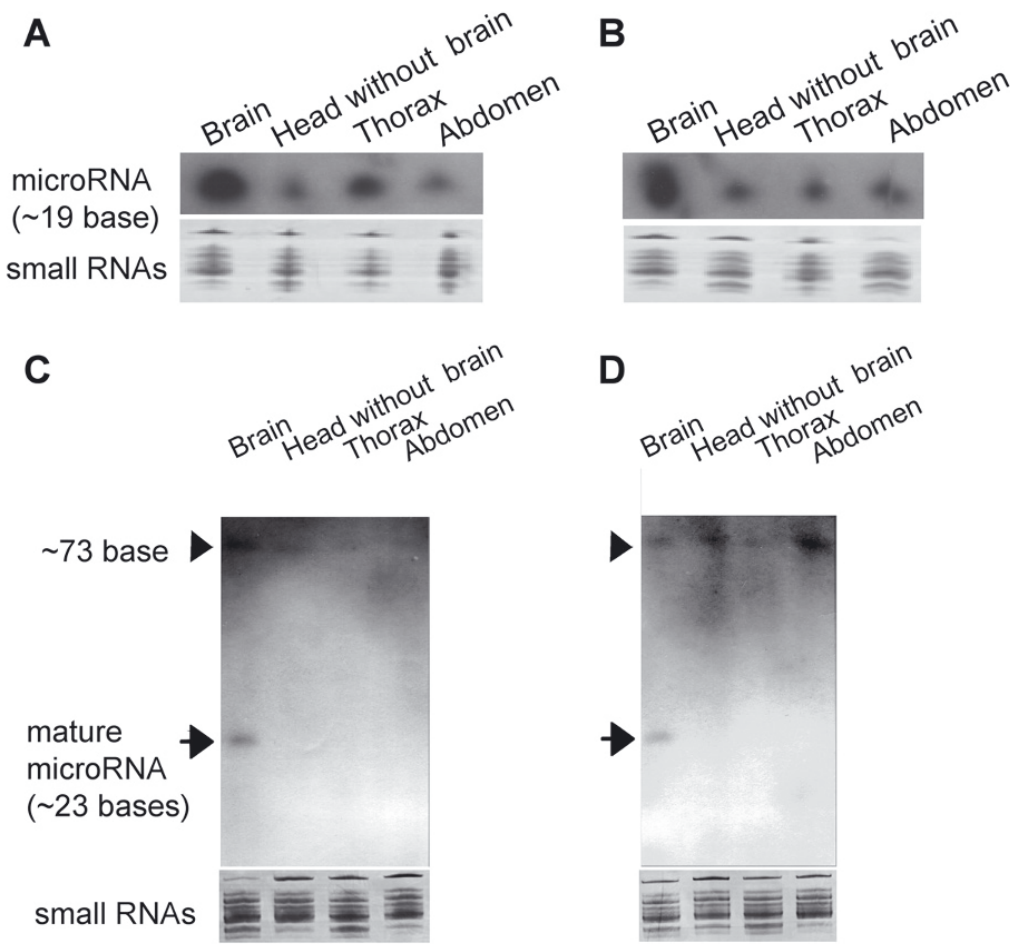

Figure 2. Northern blot analysis of ame-mir-276 and -1000 in workers and drones (A and B, upper panels) ame-mir-276-expression in workers (A) and drones (B). (Lower panels) Small RNAs (tRNAs and small subunit rRNA) were detected in a polyacrylamide gel stained with ethidium bromide to show that almost equal amounts of RNAs were subjected to electrophoresis. (C and D, upper panels) ame-mir-1000-expression in workers (C) and drones (D). The bands for mature microRNA and an additional $\sim 73 \mathrm{nt}$ bands are indicated by arrows and arrow-heads, respectively. (Lower panels) Small RNAs detected in a polyacrylamide gel stained with ethidium bromide.

detected in any of the sections hybridized with scramble-miR probes (Fig. 3E-H), indicating that the signals were due to ame-mir-276. When the hybridization time was longer, however, the signal was detected throughout the brain cortex (data not shown), indicating that ame-mir-276-expression in the brain was not region-specific, but rather preferential. Although we also tried to detect ame-mir1000 expression by in situ hybridization, no significant signals were detected (data not shown), possibly due to its low expression level.

\subsection{Target prediction}

To estimate the targets of the microRNAs identified in our experiments, we first searched for honeybee homologues of the verified target genes for the corresponding microRNA in other animal species based on canonical, seed, or $3^{\prime}$ compensatory sequences of the predicted $3^{\prime}$-UTR (Supplementary Tab. I). We found that Enhancer of split protein $(E(s p l))$ is a homologue for ame-mir-2-1/13a, wingless is a homologue for ame-mir-8, and hypothetical $c$-myc and $B c l-2$ are homologues for ame-mir-34, which contain conserved seed sequences (Supplementary Tab. I). we also analyzed homologues of the predicted target genes for ame-mir-276 and ame-mir-1000, for which no verified and only hypothetical ones have been identified (http://targetscan.org/, http://pictar.mdc-berlin.de/, respectively). The results predicted one potential ame-mir-276: zinc finger homeodomain 2 (zfh2); and eight 


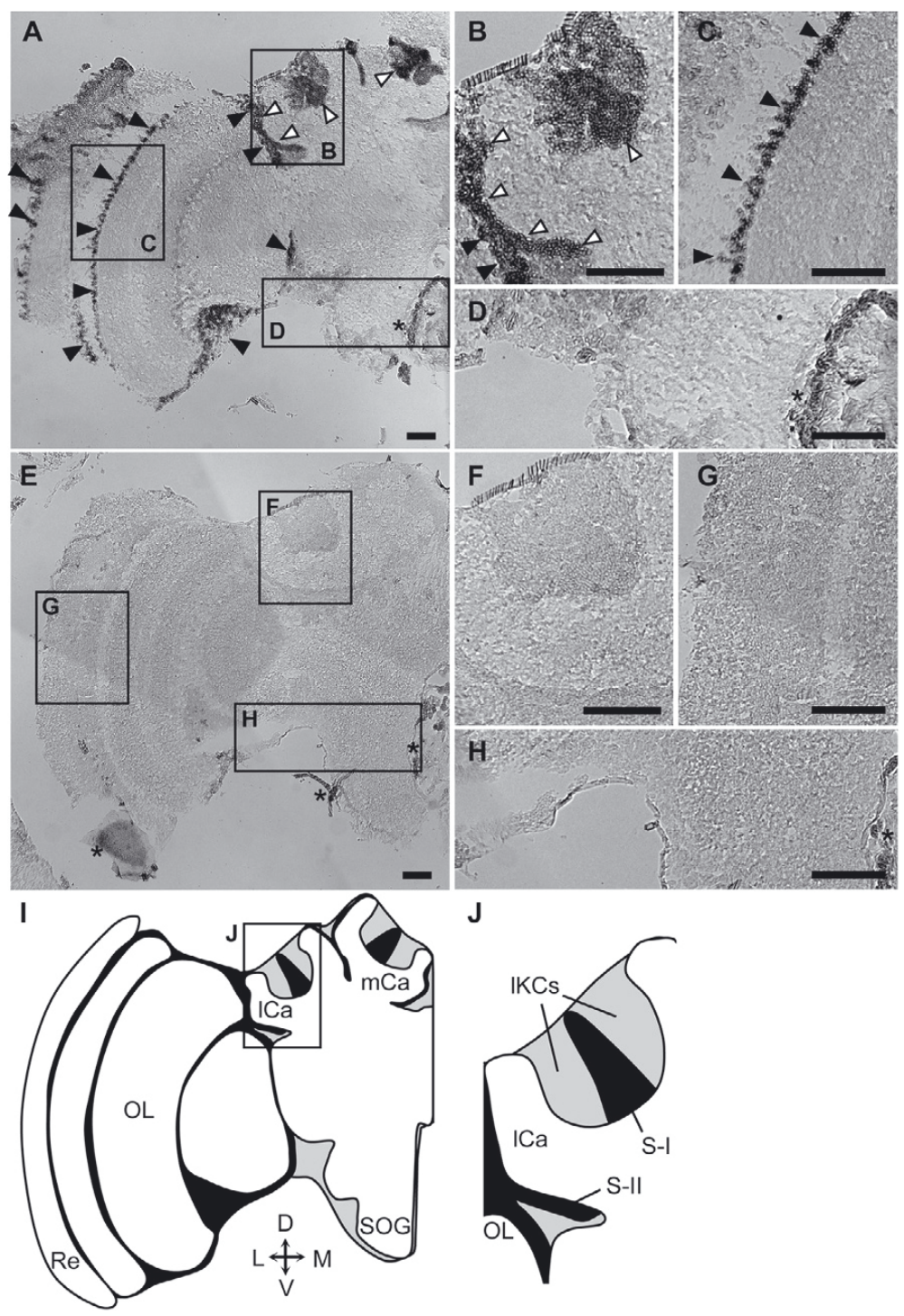

Figure 3. In situ hybridization of ame-mir-276 in the brain of nurse bees, foragers, queens and drones. In situ hybridization with DIG-labeled LNA antisense ame-mir-276 probe of the left brain hemisphere of nurse bee (A-D), forager (K-N), queen (O-R), and drone (S-V). (E-H) Nurse bee brain section hybridized with a scramble-miR probe corresponding to sections (A-D), respectively. (B-D, F-H, J, L-N, P-R, T-V) Magnified views of the boxes outlined in (A, E, I, K, O and S). The stronger signals detected in the OLs and the class I and II small-type Kenyon cells are indicated by black and white arrowheads, respectively. Scale bars indicate $100 \mu \mathrm{m}$. Asterisks indicate nonspecific staining. (I) Schematic representation of signals detected in the female bee (nurse bee, forager and queen) brain. Brain regions with strong and weak signals are indicated by black and gray, respectively. Note that one MB is composed of two (lateral and medial) calyces and the OL comprises three neuropil layer structures. slCa, lateral calyx; $m C a$, medial calyx; $l K C s$, large-type Kenyon cells; $O L$, optic lobe; $R e$, retina; $S O G$, subesophageal ganglion; $D$, dorsal; $V$, ventral; $L$, lateral; $M$, medial. (T) Magnified view of left lateral calyx boxed in panel (S). $S-I$, class I small-type Kenyon cells; S-II, class II small-type Kenyon cells. Because drone brain structure differs from that of female bees, the names of brain regions are indicated in panels ( $\mathrm{S}$ and $\mathrm{T})$. 


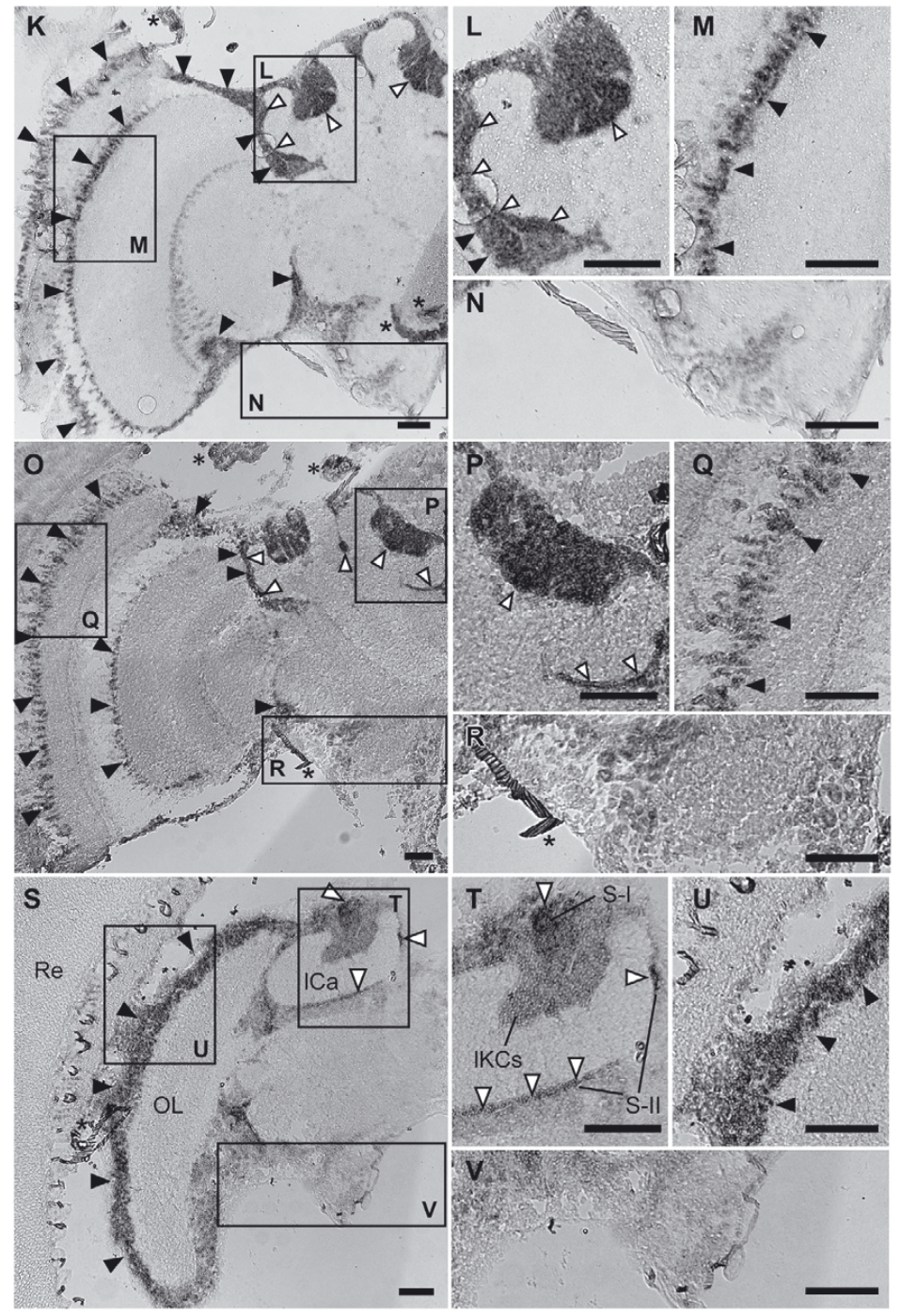

Figure 3. Continued.

potential ame-mir-1000 target genes: zinc finger homeodomain 1 (zfhl), Corin, AT-binding transcription factor 1 (ATBF1), Vesicular glutamate transporter (VGlut), hypothetical neurotransmitter transporter (CG10804), Neuro- peptide-like precursor 1 (Nplp1), dopamine beta-monooxygenase (CG34355), transcription factor net, and an unknown hypothetical gene (CG13165) for ame-mir-1000 (Supplementary Tab. I). Interestingly, almost all of these target genes are related to neural function (Supplementary Tab. I), supporting the idea that translation of these genes are regulated by microRNAs in the honeybee brain. The novel mir-hbd was located at the $3^{\prime}$ side of a gene described as "similar to E2F transcription factor 2 gene" in the honeybee genome.

\section{DISCUSSION}

In the present study, we identified eight microRNAs whose expression was enriched in the adult honeybee brain based on the cloning 
experiment. The novel mir-hbd seems to be unique to the honeybee, thus it would likely not be predicted by bioinformatics based on the previous homogeneity analysis. In Northern blot hybridization of ame-mir-276 and ame-mir-1000, the detected signal sizes were subtly different from those of the cloned or predicted sequences. Lu and colleagues reported microRNAs that reside in the same stem-loop arm and have an overlapping region (Lu et al., 2008), but such a region was not detected in our predicted precursors (data not shown).

Among cloned microRNAs, we demonstrated brain region-preferential ame-mir276-expression in the honeybee. Although dme-mir-276a is expressed during larval development, as well as in adult head and body in Drosophila (Ruby et al., 2007), its expression in adult brain has not been analyzed. We could show that ame-mir-276-expession was enriched in the OLs and the class I and II small-type Kenyon cells in the honeybee brain. Because ame-mir-276-expression is enriched in both the small-type Kenyon cells and OLs, ame-mir-276 might be involved in regulating honeybee social behaviors via the regulation of small-type Kenyon cell-preferential gene expression, as well as visual processing in the OLs. It is also possible that ame-mir-276 suppresses the expression of target mRNAs in these brain regions, resulting in a relatively high expression of its targets in other brain regions, including the large-type Kenyon cells, the subesophageal ganglion, and the ALs. Although genes expressed preferentially in all of the latter brain regions have not been reported, some genes are expressed preferentially in the large type-Kenyon cells (Kubo, 2003; Paul et al., 2006). Thus, it is possible that ame-mir-276 is partly involved in the regulation of these genes.

Although experimentally verified mir-276 target genes have not yet been demonstrated in any animal species, an $A T B F 1$ homologue containing the hypothetical zinc finger homeodomain 2 (zfh-2) was strongly predicted to be a hypothetical target in Drosophila by both TargetScanFly and PicTar-Fly with the highest predictions scores (Lundell and Hirsh, 1992). These genes encode transcription factors that regulate larval central nervous system development (Lai et al., 1991; Jung et al., 2005), but their functions in adult brain have not been demonstrated. In future studies, it will be important to first confirm whether ATBF1 is coexpressed in the small-type Kenyon cells and the OLs in the honeybee brain.

To our knowledge, ame-mir-1000 is the first microRNA identified that is expressed in a brain-selective manner in an insect. In the fruit fly, dme-mir-1000 lies within the intron of musashi (Stark et al., 2007), which encodes an RNA-binding protein expressed preferentially in the nervous system to regulate gene translation (Okabe et al., 2001). In the honeybee, ame-mir-1000 is adjacent to the predicted musashi homologue (GB18853), strongly suggesting that it also lies within the intron of honeybee musashi (Tab. I). As the transcriptional directions of mir-1000 and musashi are opposite in fruit fly, the transcription initiation sites are different between the two genes. Although musashi is not predicted to be a direct target of mir-1000 based on our target prediction, mir1000 might be related to musashi function in the nervous system.

Here, we also predicted eight candidate target genes for ame-mir-1000 (Supplementary Tab. I). Interestingly, most of them are related to neural function. Among them, zfhl, zfh2, and net encode transcription factors. Although neural functions of these genes have not been reported (Peyrefitte et al., 2001), zfh1 is structurally and functionally similar to zfh2 (Lai et al., 1991), and their expression patterns are different in the Drosophila larval central nervous system (Lai et al., 1991). Tyraminemonooxygenase $(T \beta H)$ is an insect homolog of dopamine beta-hydroxylase in mammals, which catalyzes the synthesis of octopamine from tyramine (Hess et al., 2008). In the honeybee brain, $T \beta H$-expression is localized in clusters of neurons located in the ALs and subesophageal ganglion (Lehman et al., 2006), and octopamine plays a role in olfactory learning by activating cAMP-dependent protein kinase (Hildebrandt and Müller, 1995; Farooqui et al., 2003). In addition, octopamine levels were higher in foragers than in nurse bees, although $T \beta H$-expression was similar between nurse bee and forager brains (Barron and 
Robinson, 2005; Lehman et al., 2006). Therefore, ame-mir-1000 may be involved in olfactory learning and in the division of labor of workers. VGlut and glutamate transmembrane transporter encode a neurotransmitter and transporter, respectively. VGlut is involved in the uptake and storage of the excitatory neurotransmitter L-glutamate in synaptic vesicles in nerve cells (Daniels et al., 2004, 2006). Nplp1 is expressed in the larval Drosophila central nervous system, suggesting its function in neuropeptide signaling pathways (Baggerman et al., 2002). Corin may function in cell maintenance rather than neural function (Irving et al., 2001). To verify the interaction between ame-mir-1000 and its hypothetical targets, it is necessary to confirm expression patterns of the target genes in the honeybee brain, and then to analyze their co-expression with ame-mir-1000. The ame-mir-1000 signal was not detected by in situ hybridization in the present study, suggesting that is only weakly expressed and/or that there is only a small number of neurons expressing ame-mir-1000 (data not shown).

Some of the cloned microRNAs form clusters. ame-mir-2-1 and -13a belong to the same family and cluster (Weaver et al., 2007), and are located within the intron of the similar to Serine/threonine-protein phosphatase 4 regulatory subunit 1-like gene (LOC726544). While mir-34 and -317 form a cluster in Drosophila (Aravin et al., 2003), they do not form a cluster in the honeybee (Weaver et al., 2007), and are located together within the intron of similar to CG11246-PA (LOC411083), which is a hypothetical DNA-directed RNA polymerase (Aoyagi and Wassarman, 2000). Clusters of microRNA genes are often coexpressed for the coordinated control of related biological processes (He et al., 2005; Fiore et al., 2009). Based on our finding that both ame-mir-34 and 317 are encoded in same host gene, both the ame-mir-2-1 and -13a cluster and the ame-mir-34 and -317 pair may act on related neural functions in the honeybee.

In Drosophila, mir-2 and 13 (Boutla et al., 2003), mir-34 (Ji et al., 2009), and mir-317 (predicted by TARGETSCAN and PICTARFLY) target $E(s p l)-C$ protein, $c-m y c$, and $B c l$ 2 , respectively. Their honeybee homologues also contain potential ame-mir-2-1/13 or -34 binding sites, respectively (Supplementary Tab. I). Interestingly, these three genes are all involved in the Notch signaling pathway (Oishi et al., 2004; Kosik, 2006; Orian et al., 2007). Moreover, $c$-myc and Bcl-2 regulate neurogenesis in Drosophila (Preiss et al., 1988; Orian et al., 2007), and Notch signaling is critical for the formation of long-term memory in the Drosophila MBs (Ge et al., 2004; Song et al., 2009). These microRNAs might be involved in synaptic plasticity and/or neurogenesis via the Notch signaling pathways. In our target analysis, however, we found no amemir-2-1/13 nor -34 binding site on the $3^{\prime}$ UTR of Notch (Supplementary Tab. I), suggesting that the microRNAs act downstream of Notch. For further discussion it will be necessary to confirm the co-localization of these microRNAs with their target gene transcripts and with neurogenesis in adult honeybee MBs.

Moreover, a hypothetical ame-mir- 8 binding site was detected in the 3' UTR of wingless $(W g) . W g$ has a crucial role in Drosophila brain development (Chu-LaGraff and Doe, 1993; Richter et al., 1998; Hayden et al., 2007). Because inhibitory cross-talk between $\mathrm{Wg}$ and Notch has been reported (Axelrod et al., 1996), the microRNAs may regulate the balance between the two signaling pathways in the honeybee brain.

The function and expression of other microRNAs in the brain remains obscure, although the majority of them are related to neural function in Drosophila (Supplementary Tab. I). On the other hand, independent regulation of the typical binding rules has been predicted (Didiano and Hobert, 2006), and therefore other unknown rules may be involved in the in vivo target recognition of microRNAs. Screening of genes showing an inverse correlative expression with microRNA will be the next step toward verification of the targets. In addition, gene manipulation techniques using microRNA have recently been developed in some animals (Ørom et al., 2006; Hutchison et al., 2009). Therefore, exploration of brain-selective microRNAs might lead to validation of gene functions in the honeybee, for which genetic methods have not yet been established. Further analysis of the 
brain-preferential microRNAs will provide an important clue for our understanding of the molecular basis that underlies brain regionpreferential gene expression in the honeybee.

\section{ACKNOWLEDGEMENTS}

This work was supported in part by the Program for Promotion of Basic Research Activities for Innovative Bioscience (PROBRAIN).

Expression de deux micro-ARN, ame-mir-276 et -1000, dans le cerveau de l'abeille adulte (Apis mellifera).

Apis mellifera / cerveau / expression génique différentielle / micro ARN / lobe optique / corps pédonculés

Zusammenfassung - Expression von zwei Mikro-RNAs, ame-mir-276 and -1000, im Gehirn adulter Honigbienen (Apis mellifera L.) . Die europäische Honigbiene ist ein soziales Insekt von herausragendem Sozialverhalten. Einige der in unterschiedlichen Gehirnregionen oder in bestimmten Aufgaben der Arbeitsteilung präferentiell exprimierten Gene wurden bereits als Kandidatengene für das Sozialverhalten der Honigbiene identifiziert. Mikro-RNAs sind kleine, 19-25 Basen lange, nicht kodierende, funktionelle RNAs, die die Expression von Zielgenen via Interaktion mit deren mRNAs herunterregeln. In der vorliegenden Studie, die die Untersuchung der möglichen Rolle von Mikro-RNAs in der Regulation der Genexpression im Bienengehirn zum Ziel hatte, identifizierten wir sieben bereits bekannte, ame-mir-2-1, -8, 13a, -34, -276, -317, -1000 , und eine neue Mikro-RNA, mir-hbd, als im Bienengehirn exprimiert (Tabelle I). mir-hbd erfüllt zwei der für Mikro-RNAs wichtigen Kriterien: (1) als reife Mikro-RNA hat sie eine Länge zwischen 19-25 Basen, während die Vorläufer RNA zwischen 60-100 Basen umfasst (Abb. 1), und (2) besitzt die Vorläufer RNA eine Haarnadel-Struktur (Abb. 1). Diese beiden Kriterien weisen mir-hbd als eine neue Honigbienen Mikro-RNA aus. Während ame-mir-1000 sich als im Gehirn selektiv exprimiert zeigte, erwies sich ame-mir-276 als eine im Gehirn präferentiell exprimierte Mikro-RNA (Abb. 2), und diese Befunde galten sowohl für Arbeiterinnen, als auch Drohnen. Mittels in situ Hybridisierungs-Experimenten fanden wir, dass die ame-mir-276-Expression in den optischen Loben, d.h. dem Sehzentrum, als auch in dem kleinen Kenyon-Zelltyp der Pilzkörper, einem höheren Integrationszentrum, im Gehirn von Ammenbienen, Sammlerinnen, Königinnen und
Drohnen angereichert ist (Abb. 3). Fast alle der für ame-mir-1000 und -276 vorhergesagten Zielgene kodieren für Gene mit neuralen Funktionen, was ebenfalls auf eine Rolle dieser beiden Mikro-RNAs in neuralen Funktionen hinweist. Des weiteren sind diese Befunde ein Hinweis darauf, dass sowohl ame-mir-1000 als auch -276 an der Regulation der gewebespezifischen und selektiven Expression bestimmter neuraler Subtypen der Honigbiene beteiligt sind.

\section{Mikro-RNA / differentielle Genexpression / Arbeitsteilung / optischer Lobus / Pilzkörper}

\section{REFERENCES}

Adams H.A., Southey B.R., Robinson G.E., Rodriguez-Zas S.L. (2008) Meta-analysis of genome-wide expression patterns associated with behavioral maturation in honey bees, BMC Genomics 9, 503.

Alaux C., Le Conte Y., Adams H.A., Rodriguez-Zas S., Grozinger C.M., Sinha S., Robinson G.E. (2009) Regulation of brain gene expression in honey bees by brood pheromone, Genes Brain Behav. 8, 309-319.

Ament S.A., Corona M., Pollock H.S., Robinson G.E. (2008) Insulin signaling is involved in the regulation of worker division of labor in honey bee colonies, Proc. Natl. Acad. Sci. USA 105, 4226-4231.

Aoyagi N., Wassarman D.A. (2000) Genes encoding Drosophila melanogaster RNA polymerase II general transcription factors: diversity in TFIIA and TFIID components contributes to genespecific transcriptional regulation, J. Cell Biol. 150, F45-F50.

Aravin A.A., Lagos-Quintana M., Yalcin A., Zavolan M., Marks D., Snyder B., Gaasterland T., Meyer J., Tuschl T. (2003) The small RNA profile during Drosophila melanogaster development, Dev. Cell 5, 337-350.

Axelrod J.D., Matsuno K., Artavanis-Tsakonas S., Perrimon N. (1996) Interaction between Wingless and Notch signaling pathways mediated by disheveled, Science 271, 1826-1832.

Babak T., Zhang W., Morris Q., Blencowe B.J., Hughes T.R. (2004) Probing microRNAs with microarrays: tissue specificity and functional inference, RNA 10, 1813-1819.

Baggerman G., Cerstiaens A., De Loof A., Schoofs L. (2002) Peptidomics of the larval Drosophila melanogaster central nervous system, J. Biol. Chem. 277, 40368-40374.

Barik S. (2008) An intronic microRNA silences genes that are functionally antagonistic to its host gene, Nucleic Acids Res. 36, 5232-5241. 
Barron A.B., Robinson G.E. (2005) Selective modulation of task performance by octopamine in honey bee (Apis mellifera) division of labour, J. Comp. Physiol. A 191, 659-668.

Bartel D.P. (2004) microRNAs: genomics, biogenesis, mechanism, and function, Cell 116, 281-297.

Ben-Shahar Y. (2005) The foraging gene, behavioral plasticity, and honeybee division of labor, J. Comp. Physiol. A 191, 987-994.

Boutla A., Delidakis C., Tabler M. (2003) Developmental defects by antisense-mediated inactivation of microRNAs 2 and 13 in Drosophila and the identification of putative target genes, Nucleic Acids Res. 31, 4973-4980.

Brennecke J., Stark A., Russell R.B., Cohen S.M. (2005) Principles of microRNA-target recognition, PLoS Biol. 3, e85.

Brockmann A., Annangudi S.P., Richmond T.A., Ament S.A., Xie F., Southey B.R., Rodriguez-Zas S.R., Robinson G.E., Sweedler J.V. (2009) Quantitative peptidomics reveal brain peptide signatures of behavior, Proc. Natl. Acad. Sci. USA 106, 2383-2388.

Chu-LaGraff Q., Doe C.Q. (1993) Neuroblast specification and formation regulated by wingless in the Drosophila CNS, Science 261, 1594-1597.

Daniels R.W., Collins C.A., Chen K., Gelfand M.V., Featherstone D.E., DiAntonio A. (2006) A single vesicular glutamate transporter is sufficient to fill a synaptic vesicle, Neuron 49, 11-16.

Daniels R.W., Collins C.A., Gelfand M.V., Dant J., Brooks E.S., Krantz D.E., DiAntonio A. (2004) Increased expression of the Drosophila vesicular glutamate transporter leads to excess glutamate release and a compensatory decrease in quantal content, J. Neurosci. 24, 10466-10474.

Denison R., Raymond-Delpech V. (2008) Insights into the molecular basis of social behaviour from studies on the honeybee, Apis mellifera, Invert. Neurosci. 8, 1-9.

Didiano D., Hobert O. (2006) Perfect seed pairing is not a generally reliable predictor for microRNAtarget interactions, Nat. Struct. Mol. Biol. 13, 849851.

Fahrbach S.E., Giray T., Robinson G.E. (1995) Volume changes in the mushroom bodies of adult honey bee queens, Neurobiol. Learn. Mem. 63, 181-191.

Farooqui T., Robinson K., Vaessin H., Smith B.H. (2003) Modulation of early olfactory processing by an octopaminergic reinforcement pathway in the honeybee, J. Neurosci. 23, 5370-5380.

Fiore R., Khudayberdiev S., Christensen M., Siegel G., Flavell S.W., Kim T.K., Greenberg M.E., Schratt G. (2009) Mef2-mediated transcription of the miR379-410 cluster regulates activity-dependent dendritogenesis by fine-tuning Pumilio2 protein levels, EMBO J. 28, 697-710.
Ge X., Hannan F., Xie Z., Feng C., Tully T., Zhou H., Xie Z., Zhong Y. (2004) Notch signaling in Drosophila long-term memory formation, Proc. Natl. Acad. Sci. USA 101, 10172-10176.

Griffiths-Jones S., Saini H.K., van Dongen S., Enright A.J. (2008) miRBase: tools for microRNA genomics, Nucleic Acids Res. 36, D154-158.

Grün D., Wang Y-L., Langenberger D., Gunsalus K.C., Rajewsky N. (2005) microRNA target predictions across seven Drosophila species and comparison to mammalian targets, PLoS Comput. Biol. 1, e13.

Hayden M.A., Akong K., Peifer M. (2007) Novel roles for APC family members and Wingless/Wnt signaling during Drosophila brain development, Dev. Biol. 305, 358-376.

He L., Thomson J.M., Hemann M.T., Hernando-Monge E., Mu D., Goodson S., Powers S., Cordon-Cardo C., Lowe S.W., Hannon G.J., Hammond S.M. (2005) A microRNA polycistron as a potential human oncogene, Nature 435, 828-833.

Hess C.R., McGuirl M.M., Klinman J.P. (2008) Mechanism of the insect enzyme, tyramine beta-monooxygenase, reveals differences from the mammalian enzyme, dopamine betamonooxygenase, J. Biol. Chem. 283, 3042-3049.

Heylen K., Gobin B., Billen J., Hu T.T., Arckens L., Huybrechts R. (2008) Amfor expression in the honeybee brain: a trigger mechanism for nurseforager transition, J. Insect Physiol. 54, 14001403 .

Hildebrandt H., Müller U. (1995) Octopamine mediates rapid stimulation of protein kinase $\mathrm{A}$ in the antennal lobe of honeybees, J. Neurobiol. 27, 44 50.

Hutchison E.R., Okun E., Mattson M.P. (2009) The therapeutic potential of microRNAs in nervous system damage, degeneration, and repair, Neuromol. Med. 11, 153-161.

Irving P., Troxler L., Heuer T.S., Belvin M., Kopczynski C., Reichhart J.M., Hoffmann J.A., Hetru C. (2001) A genome-wide analysis of immune responses in Drosophila, Proc. Natl. Acad. Sci. USA 98, 15119-15124.

Ji Q., Hao X., Zhang M., Tang W., Yang M., Li L., Xiang D., Desano J.T., Bommer G.T., Fan D., Fearon E.R., Lawrence T.S., Xu L. (2009) microRNA miR-34 inhibits human pancreatic cancer tumor-initiating cells, PLoS One 4, e6816.

Jung C.G., Kim H.J., Kawaguchi M., Khanna K.K., Hida H., Asai K., Nishino H., Miura Y. (2005) Homeotic factor ATBF1 induces the cell cycle arrest associated with neuronal differentiation, Development 132, 5137-5145.

Karres J., Hilgers V., Carrera I., Treisman J., Cohen S. (2007) The conserved microRNA MiR-8 tunes atrophin levels to prevent neurodegeneration in Drosophila, Cell 131, 136-145. 
Kheradpour P., Stark A., Roy S., Kellis M. (2007) Reliable prediction of regulator targets using 12 Drosophila genomes, Genome Res. 17, 19191931.

Kiya T., Kunieda T., Kubo T. (2007) Increased neural activity of a mushroom body neuron subtype in the brains of forager honeybees, PLoS One 2, e371.

Kosik K.S. (2006) The neuronal microRNA system, Nat. Rev. Neurosci. 7, 911-920.

Krek A., Grün D., Poy M.N., Wolf R., Rosenberg L., Epstein E.J., MacMenamin P., da Piedade I., Gunsalus K.C., Stoffel M., Rajewsky N. (2005) Combinatorial microRNA target predictions, Nat. Genet. 37, 495-500.

Kubo T. (2003) Molecular analysis of the honeybee sociality, in: Kikuchi T., Azuma N., Higashi S. (Eds.), Genes, Behaviors and Evolution of Social Insects, Hokkaido University Press, pp. 3-20.

Lai Z.C., Fortini M.E., Rubin G.M. (1991) The embryonic expression patterns of zfh-1 and zfh-2, two Drosophila genes encoding novel zinc-finger homeodomain proteins. Mech. Dev. 34, 123-134.

Lehman H.K., Schulz D.J., Barron A.B., Wraight L., Hardison C., Whitney S., Takeuchi H., Paul R.K., Robinson G.E. (2006) Division of labor in the honey bee (Apis mellifera): the role of tyramine beta-hydroxylase, J. Exp. Biol. 209, 2774-2784.

Lim L.P., Lau N.C., Garrett-Engele P., Grimson A., Schelter J.M., Castle J., Bartel D.P., Linsley P.S., Johnson J.M. (2005) Microarray analysis shows that some microRNAs downregulate large numbers of target mRNAs, Nature 433, 769-773.

Long J.E., Chen H.X. (2009) Identification and characteristics of cattle microRNAs by homology searching and small RNA cloning, Biochem. Genet. 47, 329-343.

Lu C., Jeong D.H., Kulkarni K., Pillay M., Nobuta K., German R., Thatcher S.R., Maher C., Zhang L., Ware D., Liu B., Cao X., Meyers B.C., Green P.J. (2008) Genome-wide analysis for discovery of rice microRNAs reveals natural antisense microRNAs (nat-miRNAs), Proc. Natl. Acad. Sci. USA 105, 4951-4956.

Lundell M.J., Hirsh J. (1992) The zfh-2 gene product is a potential regulator of neuron-specific dopa decarboxylase gene expression in Drosophila, Dev. Biol. 154, 84-94.

Mishima T., Takizaw T., Luo S.S., Ishibashi O., Kawahigashi Y., Mizuguchi Y., Ishikawa T., Mori M., Kanda T., Goto T., Takizawa T. (2008) MicroRNA (microRNA) cloning analysis reveals sex differences in microRNA expression profiles between adult mouse testis and ovary, Reproduction 136, 811-822.

Mobbs P.G. (1982) The brain of the honeybee Apis mellifera. 1. The connections and spatial organization of the mushroom bodies, Philos. Trans. R. Soc. Lond. B 298, 309-354.
Obernosterer G., Leuschner P.J., Alenius M., Martinez J. (2006) Post-transcriptional regulation of microRNA expression, RNA 12, 1161-1167.

Oishi K., Kamakura S., Isazawa Y., Yoshimatsu T., Kuida K., Nakafuku M., Masuyama N., Gotoh Y. (2004) Notch promotes survival of neural precursor cells via mechanisms distinct from those regulating neurogenesis, Dev. Biol. 276, 172-184.

Okabe M., Imai T., Kurusu M., Hiromi Y., Okano H. (2001) Translational repression determines a neuronal potential in Drosophila asymmetric cell division, Nature 411, 94-98.

Orian A., Delrow J.J., Nieves A.E.R., Abed M., Metzger D., Paroush Z., Eisenman R.N., Parkhurst S.M. (2007) A Myc-Groucho complex integrates EGF and Notch signaling to regulate neural development, Proc. Natl. Acad. Sci. USA 104, 1577115776.

Ørom U.A., Kauppinen S., Lund A.H. (2006) LNAmodified oligonucleotides mediate specific inhibition of microRNA function, Gene 372, 137-141.

Paul R.K., Takeuchi H., Kubo T. (2006) Expression of two ecdysteroid-regulated genes, Broad-Complex and E75, in the brain and ovary of the honeybee (Apis mellifera L.), Zool. Sci. 23, 1085-1092.

Peyrefitte S., Kahn D., Haenlin M. (2001) New members of the Drosophila Myc transcription factor subfamily revealed by a genome-wide examination for basic helix-loop-helix genes, Mech. Dev.104, 99-104.

Preiss A., Hartley D.A., Artavanis-Tsakonas S. (1988) The molecular genetics of Enhancer of split, a gene required for embryonic neural development in Drosophila, EMBO J. 7, 3917-3927.

Reddy A.M., Zheng Y., Jagadeeswaran G., Macmil S.L., Graham W.B., Roe B.A., Desilva U., Zhang W., Sunkar R. (2009) Cloning, characterization and expression analysis of porcine microRNAs, BMC Genomics 10, 65.

Richter S., Hartmann B., Reichert H. (1998) The wingless gene is required for embryonic brain development in Drosophila, Dev. Genes Evol. 208, 37-45.

Robinson G.E. (2002) Genomics and integrative analyses of division of labor in honeybee colonies, Am. Nat. 6, S160-172.

Robinson G.E., Fahrbach S.E., Winston M.L. (1997) Insect societies and the molecular biology of social behavior, Bioessays 19, 1099-1108.

Ruby J.G., Stark A., Johnston W.K., Kellis M., Bartel D.P., Lai E.C. (2007) Evolution, biogenesis, expression, and target predictions of a substantially expanded set of Drosophila microRNAs, Genome Res. 17, 1850-1864.

Schratt G.M., Tuebing F., Nigh E.A., Kane C.G., Sabatini M.E., Kiebler M., Greenberg M.E. (2006) A brain-specific microRNA regulates dendritic spine development, Nature 439, 283-289. 
Smirnova L., Gräfe A., Seiler A., Schumacher S., Nitsch R., Wulczyn F.G. (2005) Regulation of microRNA expression during neural cell specification, Eur. J. Neurosci. 21, 1469-1477.

Song Q., Sun K., Shuai Y., Lin R., You W., Wang L., Zhong Y. (2009) Suppressor of Hairless is required for long-term memory formation in Drosophila, J. Neurogenet. 23, 405-411.

Stark A., Kheradpour P., Parts L., Brennecke J., Hodges E., Hannon G.J., Kellis M. (2007) Systematic discovery and characterization of fly microRNAs using 12 Drosophila genomes, Genome Res. 17, 1865-1879.

Stefani G., Slack F.J. (2008) Small non-coding RNAs in animal development, Nat. Rev. Mol. Cell Biol. 9, 219-230.

Vester B., Wengel J. (2004) LNA (locked nucleic acid): high-affinity targeting of complementary RNA and DNA, Biochemistry 43, 13233-13241.

Wayman G.A., Davare M., Ando H., Fortin D., Varlamova O., Cheng H.Y., Marks D.,
Obrietan K., Soderling T.R., Goodman R.H., Impey S. (2008) An activity-regulated microRNA controls dendritic plasticity by down-regulating p250GAP, Proc. Natl. Acad. Sci. USA 105, 9093 9098.

Weaver D.B., Anzola J.M., Evans J.D., Reid J.G., Reese J.T., Childs K.L., Zdobnov E.M., Samanta M.P., Miller J., Elsik C.G. (2007) Computational and transcriptional evidence for microRNAs in the honey bee genome, Genome Biol. 8, R97.

Whitfield C.W., Cziko A.M., Robinson G.E. (2003) Gene expression profiles in the brain predict behavior in individual honey bees, Science 302, 296299.

Winston M.L. (1987) The Biology of the Honey bee, Harvard University Press, Cambridge, MA.

Yamazaki Y., Shiraia K., Paul R.K., Fujiyuki T., Wakamoto A., Takeuchi H., Kubo T. (2006) Differential expression of $H R 38$ in the mushroom bodies of the honeybee brain depends on the caste and division of labor, FEBS Lett. 580, 2667-2670. 